
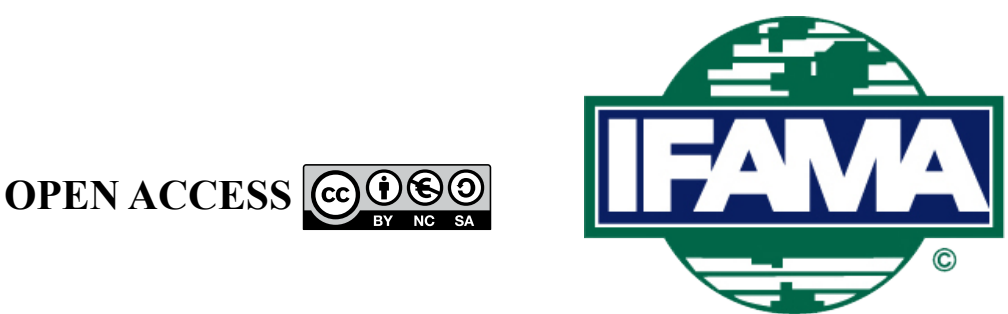

International Food and Agribusiness Management Review

Volume 25, Issue 3, 2022; DOI: 10.22434/IFAMR2020.0156

Received: 8 September 2020 / Accepted: 3 November 2021

\title{
Price transmission between international and domestic prices in the Brazilian citrus sector
}

\section{RESEARCH ARTICLE}

\author{
Mohammad Jahangir Alam ${ }^{\circledR a}$, Miguel I. Gómez ${ }^{\mathrm{b}}$, Marco Tulio Ospina Patino ${ }^{\mathrm{c}}$, \\ Milla Reis de Alcântara ${ }^{\mathrm{d}}$ and Ismat Ara Begum ${ }^{\mathrm{e}}$ \\ a Professor, Department of Agribusiness and Marketing, \\ Bangladesh Agricultural University, Mymensingh, 2202, Bangladesh \\ ${ }^{b}$ Robert G. Tobin Professor of Food Marketing, Charles H. Dyson School of Applied \\ Economics and Management, Cornell University, Ithaca, NY 14853, USA \\ ${ }^{c}$ Assistant Professor, Faculty of Agricultural Engineering, \\ State University of Campinas, Campinas, 13083-875, Brazil \\ ${ }^{d}$ Substitute Professor, Department of Applied Social Sciences, State University of Pará, Belém, 66095-015, Brazil \\ eProfessor, Department of Agricultural Economics, Bangladesh \\ Agricultural University, Mymensingh, 2202, Bangladesh
}

\begin{abstract}
The orange juice chain is a representative sector of the Brazilian agribusiness sector and its performance warrants analysis to identify strategies to enhance its competitiveness. Analysis of asymmetry in food value chain is important because it provides valuable information on market structure and performance. We use an asymmetric threshold error correction model to examine threshold, short- and long-run asymmetries on price transmission from international to domestic prices of oranges in Brazil. We use monthly data on international frozen concentrated orange juice prices and domestic prices of oranges in Brazil for the period from January 1996 to December 2020 in the analysis. We find evidence of threshold and asymmetries in short- and longrun price transmission and asymmetric adjustment towards a long-run relationship between international and domestic orange prices in Brazil. Decreases in international prices that lead to reductions in marketing margins are passed on quickly to domestic prices, but this is not the case for increases in international prices. We discuss implications for the Brazilian citrus industry.
\end{abstract}

Keywords: price transmission, citrus industry, cointegration, asymmetry threshold error correction model JEL code: C22, C51, Q13, Q18

\footnotetext{
(i) Corresponding author: alambau2003@yahoo.com / mjahangir.alam@bau.edu.bd
} 


\section{Introduction}

One of the most competitive and of largest growth potential sectors in Brazilian agribusiness is the orange juice industry. As indicated by Neves et al. (2013) Brazil is the largest producer and exporter of orange juice worldwide, responsible for 53\% of global production and exporting roughly $95 \%$ of the domestic production. In 2020, exports from the Brazilian citrus industry reached US\$ 1.8 billion in revenue, representing about $2 \%$ of Brazilian total agribusiness exports.

The citrus chain is present in over three thousand Brazilian municipalities, and generates more than two hundred thousand direct and indirect jobs. In Brazil, 30\% of the national production is consumed each year as fresh fruit and the other $70 \%$ of the national production is processed into orange juice, of which $98 \%$ is exported, making this industry an important source of foreign currency and revenue to the country (Neves et al., 2014).

The devaluation of the US dollar against the Brazilian Real (approximately 171\%), coupled with rising costs for stakeholders along the supply chain, caused the average cost of processing oranges to rise $224 \%$ from 2003 to 2010, jumping from US\$ 347.54 to US\$ 534.28 per ton of frozen concentrated orange juice (FCOJ) (Neves et al., 2013). Also, in recent years, Brazilian orange producers had to deal with increases of infected orchards by HLB (commonly known as citrus greening). Despite these difficulties, the orange juice supply chain is a critical sector of the Brazilian agro-industrial sector and its performance warrants analysis to identify strategies that enhance its competitiveness.

Santos (2003) shows that increased integration of Brazilian citrus companies, particularly in the 1980s, led to substantial investments in own orchards and expansion of the Brazilian participation in the international market. The expansion of Brazilian participation in the international orange market attracted a large number of independent orange growers in the 1980s and 1990s. With the increase of independent growers selling to a consolidating processing export sector for the export market, prices along the supply chain became very volatile and citrus growers had difficulty maintaining their profitability due to increased price risk. Transactions were primarily based on individual negotiations between processors and growers, instead of contracts to manage the risk created by price volatility. This caused a reduction in orange prices coupled with increases in production costs for growers. Large numbers of orange growers exited the market, creating more price volatility and leading to higher concentration of production. While the advantage to processors from having their own orchards come from the flexibility to purchase oranges from independent growers, when orange market prices are low own production by processors become disadvantageous because their ability to reduce costs are limited (Santos, 2003).

In this context, examining price transmission between international prices of FCOJ (i.e. price received by the industrial processors exporting the concentrate) and domestic orange prices (i.e. prices received by growers) is fundamental to understand market performance and possible market power exerted by processors over domestic orange growers. Although some studies have investigated price transmission between international and domestic orange prices in Brazil (e.g. Figueiredo et al. 2013; Silva et al. 2017), recent methodological advances and the availability of longer time series warrant additional research on this critical topic of the Brazilian orange supply chain. To fill this gap in the literature, the primary objective of this study is to employ a novel method (asymmetric threshold error correction model (ATECM)) using monthly price data for the period January/1996-December/2020, to investigate price transmission asymmetries internationalto-domestic price transmission within citrus sector in Brazil. In addition to the identifying short- and longrun asymmetries in price transmission, the ATECM allows us to explore asymmetries in thresholds of price response. For example, asymmetric thresholds consider the possibility that domestic prices may be more (less) sticky responding to positive (negative) changes in international prices, or vice versa. We use the results to measure the significance and the magnitude of asymmetries as well as the implications for market performance and behavior of the Brazilian orange export supply chain. 
Similar market structure and price volatility have been examined by numerous empirical studies of other food products. This literature shows that increases in factor prices are often transmitted more quickly to end users than decreases in factor prices (Lass, 2005, Meyer and Von Cramon Taubadel, 2004; Serra and Goodwin, 2003). This observed behavior is particularly relevant to the study of price spreads in global food value chains given the rapid concentration in food processing and retailing worldwide (McLaughlin, 2006). Identifying asymmetries in price transmission is relevant to market practitioners for the design of supply chain strategies to enhance performance (e.g. profitability, cost efficiency, etc.). In addition, the study of price transmission is relevant to policy makers concerned about overseeing possible anti-competitive practices in global food value chains.

The paper is structured as follows. After this introduction, Section 2 discusses price transmission asymmetries and the citrus market. Section 3 presents the modeling framework followed by data and time series properties in Section 4. The results and their discussion are presented in Section 5; and Section 6 concludes and suggests areas for further research.

\section{Price transmission asymmetries and the citrus market}

Interest in the study of price transmission mechanisms dates to Keynesian economics postulates explaining the process of wage and prices adjustment over time. A number of empirical studies identified the presence of price transmission asymmetries (PTAs) in aggregate price adjustments and led economists to develop theories explaining them (Mankiw and Romer, 1991; Peltzman, 2000). Price transmissions asymmetries are viewed as the result of microeconomic price setting frictions such as costs associated with price adjustments as well as the staggered timing of price changes and inventory management (Levy et al., 1997). At a more aggregate level, PTAs are regarded as the consequence of imperfect competition, including demand externalities and coordination failures (Borenstein et al., 1997; Neumark and Sharpe, 1992). These principles have been widely employed to construct testable models of PTAs in vertical and spatial price transmission for markets of agricultural commodities and food products (Azzam, 1999; Bailey and Brorsen, 1989; Kinnucan and Forker, 1987; Lee and Gomez, 2013; Ward, 1982; Xia, 2009).

Econometric methods employed in the studies of PTAs have changed over time. Earlier empirical procedures developed by Wolffram (1971) and later improved by Houck (1977) focused on differences in responses of aggregate supply functions to positive and negative changes in prices. Many assessments of PTAs in the food system adopted these methodologies to the study of price transmission with mixed results (Appel, 1992; Boyd and Brorsen, 1988; Hansmire and Willet, 1992; Kinnucan and Forker, 1987; Zhang et al., 1995). Nevertheless, Von Cramon-Taubadel (1998) points out that these studies may be biased because they disregard the time series properties of the data. Specifically, ignoring that properties of prices at different levels of the supply chains are often co-integrated may lead to spurious results.

More recently, attention has turned to empirical procedures based on the model developed by Engle and Granger (1987) and extended by Granger and Lee (1989) to test for PTA behavior. The authors develop a formal model showing that when two price series are co-integrated, there exists an error correction (EC) representation that describes their short- and long-run relationships as well as the inherent price transmission mechanism. Indeed, the second half of the 1990s has seen increased interest in EC models to study PTAs in several contexts, including gasoline prices (Balke et al., 1998; Borenstein et al., 1997), interest rates (Frost and Bowden, 1999), and consumer products (Peltzman, 2000).

Von Cramon-Taubadel and Loy (1996) pioneered the application of EC models to examine PTAs in markets for agricultural commodities and challenge methods utilized to discuss price asymmetry in the international wheat markets. The advantages of EC models to investigate PTAs when price series are co-integrated are formalized later in Von Cramon-Taubadel and Loy (1999). Subsequent studies employ EC models to examine PTAs primarily in markets for meats (Ben-Kaabia et al., 2005; Goodwin and Holt, 1999; Miller and Hayenga, 2001; Sanjuan and Gil, 2001; Von Cramon-Taubadel, 1998) and dairy products (Lass, 2005; Romain et al., 
2002; Serra and Goodwin, 2003). These studies provide evidence of short-run PTAs along supply chains for agricultural commodities.

Within the Brazilian context Figueiredo et al. (2013) find that orange juice processing companies transfer price decreases for growers in the short run, but they do not transfer price increases. The study also finds asymmetric price transmission in the long run. These results provide evidence of market power used by processors, generating cumulative losses for Brazilian citrus growers.

Recent research by Silva et al. (2017) found evidence of price transmission asymmetries within the Brazilian orange sector, with juice price increases being transmitted to growers in smaller proportions than juice price decreases in the short run.

To our knowledge, Goetz et al. (2008) is the only study that examines price the transmission mechanism between international domestic citrus market, focusing on the Israeli export citrus market. The authors use an asymmetric error correction model to demonstrate price transmission asymmetries in the first years after liberalization in 1991, but symmetric behavior in the second half of the 1990s. No previous studies examined international-to-domestic price transmission in the Brazilian market. Therefore, this study extends research on price transmission in orange juice market by testing threshold, and short- and long-run PTAs between international-to-domestic prices in Brazil, the largest orange juice exporting country.

\section{Empirical model of asymmetric price transmission}

PTAs can occur in the short- and long-run, depending on the stochastic process governing prices. Consider, for instance, two price series that are assumed to be interdependent. The differences between positive and negative changes accumulate over time leading to a non-stable long-run equilibrium. In contrast, if two time series are integrated and not cointegrated, long-run PTA is inconsistent with theory and only short-run asymmetries are possible (Von Cramon-Taubadel and Loy, 1996). Abdulai (2000) developed threshold cointegration tests that allow for asymmetric adjustment towards a long-run equilibrium relationship to examine price linkages across maize markets in Ghana. This paper confirmed that wholesale maize prices in local markets respond more swiftly to price increases than to price decreases in central markets. Abdulai (2002) employed a similar model to analyze asymmetry in price transmission between producer and retail prices in the Swiss swine-pork supply chain. The authors find that price transmission between the producers and retailers is asymmetric. Awokuse and Xiaohong (2009) examines the effect of nonlinear threshold dynamics on asymmetric price transmission for three U.S. dairy products using threshold error correction model. The paper finds that price transmission of changes between producer and retail stages of the supply chain is asymmetric for butter and fluid milk and concluded that the previous studies assumed symmetric behavior and ignored threshold may be misleading. Lee and Gómez (2013) employs the threshold cointegration model of Enders and Granger (1998) to analyze asymmetry in price transmission between international and retail prices and the impact of the elimination of the export quota system (EQS) in the global coffee supply chain. The authors compare the periods of EQS and post-EQS. The paper confirms that the threshold and asymmetry in short and long-run price transmission between international-to-retail price of coffee in Germany, USA and France during the post-EQS period.

Following the above literature, consider a long-run relationship between international prices and domestic prices expressed as:

$$
P D_{t}=\alpha+\beta W P_{t}+\mu_{t}
$$

Where the $P D_{t}$ and $W P_{t}$ are domestic prices and international prices, assumed to be $I(1), \alpha$ is transportation and quality differences, $\beta$ is the estimated long-run coefficient and the error term $\mu_{t}=P D_{t}-\alpha-\beta_{1} W P_{t}$ can be serially correlated. If the error term $\mu_{t}$ is stationary, domestic price and international prices are said to be 
cointegrated. To examine cointegrations, the Augmented Dickey-Fuller (ADF) on the estimated residuals is often employed:

$$
\Delta \hat{\mu}_{t}=\rho \hat{\mu}_{t-1}+\sum_{i=1}^{k} \Psi_{i} \Delta \hat{\mu}_{t-i}+\varepsilon_{t}
$$

Following Enders and Granger (1998) we incorporate two important features of price transmission such as existence of threshold and possible long- and short-run asymmetries in price transmissions. In the presence of threshold effects, Equation 2 can be re-written as:

$$
\Delta \hat{\mu}_{t}=I_{t}\left[\rho_{0}{ }^{\text {OUT }}+\rho_{1}{ }^{\text {oUT }} \hat{\mu}_{t-1}\right]+\left(1-I_{t}\right)\left[\rho_{0}{ }^{I N}+\rho_{1}{ }^{I N} \hat{\mu}_{t-1}\right]+\sum_{i=1}^{k-1} \Psi_{i} \Delta \mu_{t-i}+\varepsilon_{t}
$$

Where the autoregressive (AR) term of residuals $\left(\mu_{t}\right)$ can be separated into two regimes namely the 'IN' and the 'OUT' depending on whether the threshold variable $\left|\mu_{\mathrm{t}-\mathrm{d}}\right|$ exceeds a threshold value $\gamma$. The threshold $\gamma$ is unknown and needs to be estimated. The 'IN' regime defines deviations of magnitudes smaller than the threshold $\gamma$, i.e. it is inside threshold interval $[-\gamma, \gamma]$. The 'OUT' regime defines when the deviations are outside the threshold interval $[-\gamma, \gamma] . I_{t}$ is an indicator function.

The Heaviside indicator function $\left(I_{t}\right)$ is defined below in Equation 4:

$$
I_{t}=\left\{\begin{array}{l}
1 \text { if }\left|\mu_{t-d}\right| \geq \gamma \\
0 \text { if }\left|\mu_{t-d}\right|<\gamma
\end{array}\right.
$$

Where $\gamma$ represents a threshold by which movements toward the long-run equilibrium relationships are asymmetric, $d$ is a delay parameter which represents the delay in the change from one regime to the other. The $\mathrm{d}$ is determined through statistical procedure (Lee and Gómez, 2013). The sufficient conditions for the stationarity of $\hat{\mu}_{\mathrm{t}}$ are $\rho_{0}<0, \rho_{1}<0$ and $\left(1+\rho_{0}\right)\left(1+\rho_{1}\right)$ (Petrucelli and Woolford, 1984). The Equations 1, 3 and 4 together form threshold auto-regressive (TAR) model.

The Heaviside indicator function depends on the level of $\mu_{t-1}$ but the decay could depend on $\Delta \mu_{t-1}$. This is especially important when the adjustment is asymmetric and process exhibits lopsided 'momentum' in one direction than the other (Enders and Granger, 1998). If $\left|\rho_{0}\right|<\left|\rho_{1}\right|$, the momentum-threshold autoregressive (MTAR) exhibits little adjustment for positive $\Delta \hat{\mu}_{t-1}$ but substantial decay for negative $\Delta \hat{\mu}_{t-1}$ meaning that increases tend to persist but decreases tend to revert quickly back to the attractor irrespective of where disequilibrium is relative to attractor (Enders and Granger, 1998). The Heaviside indicator function can be expressed as in Equation 5. The Equations 1, 3 and 5 together form MTAR model.

$$
I_{t}= \begin{cases}1 & \text { if }\left|\Delta \mu_{t-d}\right| \geqslant \gamma \\ 0 & \text { if }\left|\Delta \mu_{t-d}\right|<\gamma\end{cases}
$$

Assuming that $P D_{t}$ and $P W_{t}$ are cointegrated, the general model of an EC representation yields

$$
\Delta P_{i, t}=\alpha_{i} E C T_{i, t-1}+\sum_{k=1}^{k} \beta_{i} \Delta P_{i, t-k}+\sum_{k=1}^{k} \beta_{i} \Delta P_{i, t-k}+\varepsilon_{i, t}
$$

Where $\mu_{t}=P D_{t}-\alpha-\beta P W_{t}$. The ECT on the right-hand side is the error correction term representing the deviations from the equilibrium in the previous period.

The EC model in Equation 6 can be re-written as threshold error correction model (TECM) in Equation 7 as follows:

$$
\Delta P_{i, t}=I_{t}\left[\rho_{0}{ }^{\text {oUT }}+\rho_{1}{ }^{\text {oUT }} \hat{\mu}_{t-1}\right]+\left(1-I_{t}\right)\left[\rho_{0}{ }^{I N}+\rho_{1}{ }^{I N} \hat{\mu}_{t-1}\right]+\sum_{i=1}^{k} \beta_{i} \Delta P_{i, t-i}+\sum_{j=0}^{K} \alpha_{j} \Delta X_{t-j}+\varepsilon_{i, t}
$$

Where $P_{i}$ is a price vector, $X_{i}$ is a vector of exogenous variables and the error term $\varepsilon_{i}$ follows a white noise process. To identify the existence of threshold effects in the error term we employ (Tsay, 1989) in where we estimate a method of recursive least squares to examine if the coefficients of AR process of EC terms 
are constant. We estimate MTAR-F statistics to test the null of linear process and rejection of it indicates the existence of threshold.

If the threshold effects in the AR process of error term is confirmed the threshold $\gamma$ is estimated using a grid search approach proposed by (Chan, 1993). The threshold values are estimated through a search over all possible threshold values minimizing the sum of squares errors (SSE). The estimated residual series, a possible threshold variable is first sorted in ascending order, the largest and the smallest $15 \%$ of residual series are eliminated and remaining $70 \%$ of the values are considered as possible thresholds. The estimated threshold yielding the lowest SSE is chosen as appropriate threshold. Hansen (1997) argued that null hypothesis of linearity in the AR process does not follow a standard distribution, therefore the conventional test is not appropriate. Hansen proposed a Chow-type test for threshold values in where he used simulations method and provided $P$-values based on bootstrap simulations (Goodwin and Holt, 1999; Goodwin and Piggott, 2001; Lee and Gómez, 2013). We use (Hansen, 1997) to estimate the maximum F-statistics and $P$-values using bootstrap methods.

Hitherto we assume a unidirectional relationship between $P D_{t}$ and $P W_{t}$. But it is possible that these two prices are determined simultaneously. Consequently, we conduct weak exogeneity tests to examine whether the cointegrating equation influences both prices. Identification of the short-run dynamics needs at least one restriction on each equation. According to the Granger representation theorem (Engle and Granger, 1987), the existence of threshold cointegration justifies estimating TECM. The model allows to nest together the short-run and long-run dynamics. A simultaneous representation of equations in TECM can be written as:

$$
\begin{aligned}
& \Delta D P_{t}=\alpha_{0}+\alpha_{1}{ }^{\text {OUT }} I_{t} \hat{\mu}_{t-1}{ }^{\text {oUT }}+\alpha_{1}{ }^{I N}\left(1-I_{t}\right) \hat{\mu}_{t-1}{ }^{I N}+\sum_{j=1}^{k} \alpha_{2, j} \Delta D P_{t-j}+\sum_{j=0}^{k} \alpha_{3, j} \Delta W P_{t-j}+\sum_{j=0}^{K} \alpha_{4, j} \Delta X_{t-j}+\varepsilon_{1, t} \\
& \Delta W P_{t}=\beta_{0}+\beta_{1}{ }^{\text {OUT }} I_{t} \hat{\mu}_{t-1}{ }^{\text {oUT }}+\beta_{1}{ }^{I N}\left(1-I_{t}\right) \hat{\mu}_{t-1}{ }^{I N}+\sum_{j=1}^{k} \beta_{2, j} \Delta D P_{t-j}+\sum_{j=0}^{k} \beta_{3, j} \Delta W P_{t-j}+\sum_{j=0}^{K} \beta_{4, j} \Delta X_{t-j}+\varepsilon_{2, t}
\end{aligned}
$$

Where, the term $\hat{\mu}_{t-1}{ }^{\text {oUT }}$ represents the deviations from the long-run equilibrium which is larger than the absolute value of threshold $\gamma$ and $\hat{\mu}_{t-1}{ }^{I N}$ represents the deviations from the long-run equilibrium within the threshold interval $[-\gamma, \gamma], X_{i, t}$ are the vector of identifying variables such as exchange rate and rainfall for the short-run parameters. We employ the system of Equations $8 \mathrm{a}$ and $8 \mathrm{~b}$ to examine threshold asymmetries between international-to-domestic price transmission.

Possible short-run asymmetries in price transmission can be examined by splitting the contemporary and lags of independent variables and lags of endogenous variables into possible and negative changes (Von Cramon-Taubadel and Loy, 1996; Lee and Gómez, 2013). For example, $\Delta^{+} D P_{t}=\Delta D P_{t}$ if $\Delta^{+} D P_{t} \geq 0$, zero otherwise; and $\Delta^{-} D P_{t}=\Delta D P_{t}$ if $\Delta^{+} D P_{t}<0$, zero otherwise (we used the same transformation for $\Delta W P_{t}$ and $\left.\triangle E x R_{t}\right)$. Incorporating the threshold asymmetry and asymmetries in short-run price responses, the models ( $8 \mathrm{a}$ and $8 \mathrm{~b}$ ) become ATECM. A simultaneous representation of the system of Equations $8 \mathrm{a}$ and $8 \mathrm{~b}$ can be re-written as ATECM model in Equations 9a and 9b:

$$
\begin{aligned}
\Delta D P_{t} & =\alpha_{0}+\alpha_{1}{ }^{\text {OUT }} I_{t} \hat{\mu}_{t-1}{ }^{\text {ouT }}+\alpha_{1}{ }^{I N}\left(1-I_{t}\right) \hat{\mu}_{t-1}{ }^{I N}+\sum_{i=1}^{k} \alpha^{+}{ }_{2, i} \Delta^{+} D P_{t-i}+\sum_{i=1}^{k}{\alpha^{-}, i}_{2} \Delta^{-} D P_{t-i} \\
& +\sum_{i=0}^{k} \alpha^{+}{ }_{3, i} \Delta^{+} W P_{t-i}+\sum_{i=0}^{k} \alpha^{-}{ }_{3, i} \Delta^{-} W P_{t-i}+\sum_{i=0}^{k} \alpha^{+}{ }_{4, i} \Delta^{+} E x R_{t-i}+\sum_{i=0}^{k} \alpha^{-}{ }_{4, i} \Delta^{-} E x R_{t-i} \\
& +\sum_{i=0}^{k} \alpha_{5, i} Z_{t-i}+v_{1, t}
\end{aligned}
$$




$$
\begin{aligned}
\Delta W P_{t} & =\omega_{0}+\omega_{1}{ }^{\text {UUT }} I_{t} \hat{\mu}_{t-1}{ }^{\text {oUT }}+\omega_{1}^{I N}\left(1-I_{t}\right) \hat{\mu}_{t-1}{ }^{I N}+\sum_{i=1}^{k} \omega^{+}{ }_{2, i} \Delta^{+} W P_{t-i}+\sum_{i=1}^{k} \omega^{-}{ }_{2, i} \Delta^{-} W P_{t-i} \\
& +\sum_{i=0}^{k} \omega^{+}{ }_{3, i} \Delta^{+} D P_{t-i}+\sum_{i=0}^{k} \omega^{-}{ }_{3, i} \Delta^{-} D P_{t-i}+\sum_{i=0}^{k} \omega^{+}{ }_{4, i} \Delta^{+} E x R_{t-i}+\sum_{i=0}^{k} \omega^{-}{ }_{4, i} \Delta^{-} E x R_{t-i} \\
& +\sum_{i=0}^{k} \omega_{5, i} Z_{t-i}+v_{2, t}
\end{aligned}
$$

Equation 9a is the ATECM model for the domestic prices and Equation 9b is the ATECM model for the international prices. The exogenous variables - 'ExR' is exchange rate from Brazilian Real to US\$ and ' $Z$ ' is rainfall. The Equations $9 \mathrm{a}$ and $9 \mathrm{~b}$ are estimated using seemingly unrelated regression (SUR) and ordinary least squares (OLS) and the Akaike information criterion (AIC) is used to select the model. We estimate SUR model because it is likely that international prices and domestic prices are determined simultaneously. From Equation 9a and 9b, we test threshold asymmetry (i.e $\alpha_{1}{ }^{O U T}=\alpha_{1}{ }^{I N}$ ), and short-run asymmetries (i.e. $\alpha_{3, i}^{+}=\alpha_{3, i}^{-} ; \alpha_{4, i}^{+}=\alpha_{42, i}^{-}$) in domestic price equation and threshold asymmetry (i.e $\omega_{1}{ }^{\text {OUT }}=\omega_{1}{ }^{I N}$ ), and short-run asymmetries (i.e. $\omega_{3, i}^{+}=\omega_{3, i}^{-} ; \omega_{4, i}^{+}=\omega_{42, i}^{-}$) in international price equation. We also test the null of symmetry in the sense that the sum of positive estimates equals to sum of negative estimates in the short-run price responses (Alam et al., 2016) as follows:

$$
H_{0}: \sum_{i=0}^{3} \beta_{i} \Delta W P_{(o)}{ }^{+}=\sum_{i=0}^{3} \beta_{i} \Delta W P_{(o)}^{-} \text {and } H_{0}: \sum_{i=0}^{3} \beta_{i} \Delta P P_{(o)}{ }^{+}=\sum_{i=0}^{3} \beta_{i} \Delta P P_{(o)}{ }^{-}
$$

The sequential steps are followed to model the threshold and PTAs between the international-to-domestic prices of orange in Brazil. First, the order of integration and cointegration are tested using unit root and Johansen (1995) cointegration tests. We test causality putting the restriction on vector error correction model (VECM) to identify the exogeneity - the price leadership role between the international-to-domestic prices. We perform the Wald-test. Second, to identify the deviations from the long-run equilibrium the long-run relationship equation is estimated using OLS in the first stage. The long-run relationship equation is estimated with respect to international prices. Based on the deviations identified in the long-run equation, we estimate the TAR and the MTAR models. We use different lag length criteria such as AIC and Bayesian information criterion (BIC) to make the residuals a white noise. In estimating TAR (consistent-TAR) and MTAR (consistentMTAR) models, the study considers two cases: (1) null threshold; and (2) estimated threshold. Third, we examine possible threshold effects using (Tsay, 1989) and estimate the delay parameter. Once threshold effect is confirmed the threshold is estimated using Chan's (1993) approach. We test the significance of threshold using Hansen (1997). Finally, we estimate ATECM using SUR and OLS and examine which model fits better to the data. The ATECM is subjected to diagnostic check. We conduct model diagnostics for serial correlation, heteroskedasticity, non-normality and model stability. The short- and long-run asymmetries are tested using F-statistics from the estimated ATECMs.

\section{Data and time series properties of data}

This analysis employs monthly data on international FCOJ prices from 1996 to 2014 (Bloomberg, 2014) and from 2015 to 2020 (CITRUSBR, 2021), as well as domestic producer prices of oranges in Brazil for the period from January 1996 to December 2020 (CEPEA, 2014). Producer orange prices were converted into US dollars per pound equivalent of one pound of FCOJ received by the producers in Brazil and international FCOJ prices are based on values from the New York Board of Trade. The monthly average rainfall in Bebedouro, a city in the State of Sao Paulo recognized as reference in oranges production to control for weather patterns effects on orange prices (CIIAGRO, 2021).

Figure 1 shows monthly international and domestic prices of oranges in Brazil. The Figure suggests that domestic prices of orange tend to move similarly to changes in international FCOJ prices. We provide descriptive statistics of domestic prices, international prices, exchange rate and rainfall in Table 1. 


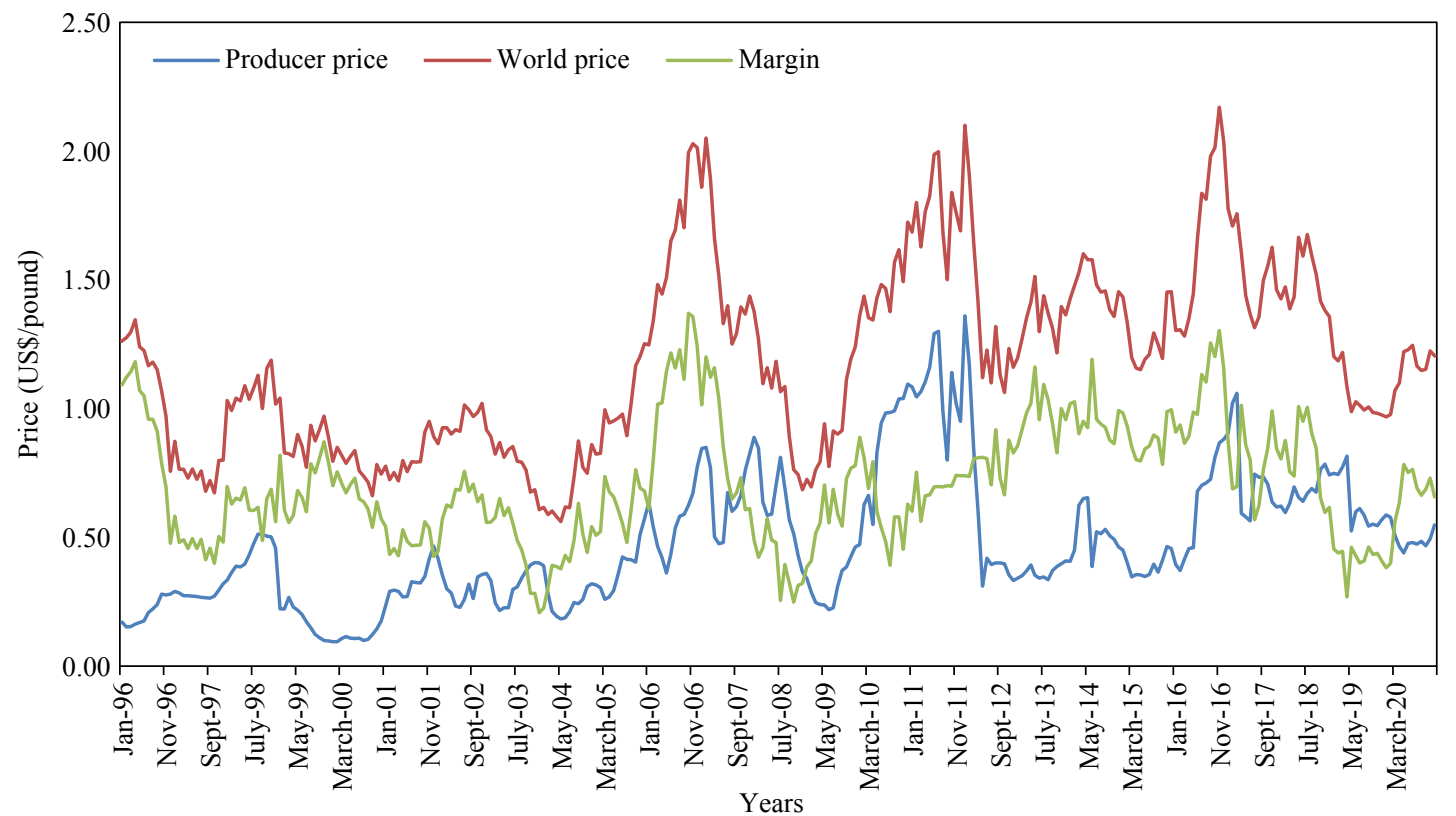

Figure 1. International prices, domestic prices, and margins of oranges.

Table 1. Descriptive statistics.

\begin{tabular}{lllllll}
\hline Variables & Mean & Max & Min & Std. Dev. & Skewness & Kurtosis \\
\hline Domestic prices & 0.477 & 1.360 & 0.095 & 0.255 & 0.966 & 3.659 \\
International prices & 1.185 & 2.170 & 0.561 & 0.359 & 0.470 & 2.524 \\
Exchange rate (BRL-US\$) & 0.479 & 1.022 & 0.177 & 0.201 & 1.063 & 3.653 \\
Rainfall & 106.98 & 560.20 & 0.000 & 105.736 & 1.246 & 4.226 \\
\hline
\end{tabular}

${ }^{1}$ Std.Dev $=$ standard deviation.

Most tests of integration assume non-stationarity under the null hypothesis and often fail to reject. The ADF and the Phillips-Perron (PP) tests are examples of this approach. However, simulations have shown that, in small samples, both tests show lower diagnostic power than the DF-GLS-test (Elliott, 1999; Elliott et $a l ., 1996)$. Therefore, we test for stationarity under the null and under the alternative hypothesis. The most commonly used test under the null of stationarity is the Lagrange-Multiplier test (Kwiatowski et al., 1992), also known as the KPSS-test.

We conduct ADF and PP tests with non-stationarity under the null and KPSS with stationarity under the null. Our results suggest that domestic prices as well as international prices contain unit roots with drift or with drift and trend. However, the null hypotheses for the price series in first differences are rejected in the cases of ADF and PP and accepted in the case of KPSS indicating that all price series are $I(1)$. In addition, we construct Zivot-Andrews (ZA) (1992) test with non-stationarity under the null hypothesis against the alternative of stationarity with single break. Similar to ADF, PP and KPSS, we find that price series are I(1). Since the break dates identified by ZA test are not consistent in one hand and to our knowledge we do not find any policy or shock corresponds to the periods identified on the other, we do not consider break point in our subsequent estimation in modelling threshold and asymmetries. 


\section{Results and discussion}

Johansen (1992a,b, 1995) proposed tests to determine whether two $I(1)$ price series are cointegrated. These tests identify the number of equations that determine the cointegration relationship between price series. The tests are based on the matrix of canonical correlations. One approach is the trace test (Johansen, 1988), which is a likelihood ratio test. The principle is to determine how many eigenvalues equal one, and the test is carried out until the null hypothesis cannot be rejected. The second approach, the maximum eigen-value test, addresses the significance of the estimated eigenvalues.

Cointegration tests are sensitive to the structure of the data generating process - the underlying deterministic process (e.g. the presence of linear trends). Johansen (1992b) suggests testing the joint hypothesis of both rank order and deterministic components. Consequently, our strategy is to move from the most restrictive model (1) to the least restrictive model (3). At each stage the test statistics are compared to their critical values. These tests are conducted as long as the null hypothesis is rejected. We conduct trace and maximum eigen value tests for domestic prices with respect to the international prices. The tests results are presented in Table 2, where $r$ is the number of cointegrating vectors. According to the trace and maximum eigen-value tests, we find that there is one cointegrating vector between the domestic prices and international prices meaning that the two price series are cointegrated. The null hypothesis of no cointegration is rejected against the alternative of at least one cointegration vector with $P$-value of $5 \%\left(\mathrm{LR}_{\text {trace }}=23.288\right)$ whereas null of one cointegration vector could not be rejected $\left(\mathrm{LR}_{\text {trace }}=7.369\right)$ (no linear trend model). The maximum eigenvalue tests provide similar results. However, since the two price series are cointegrated, there must exist an ECT that corrects the deviations from their long-run equilibrium.

Next, we present results from weak exogeneity and long-run causality tests corresponding to the bivariate Johansen VECM. Results presented in Table 3 indicate that deviations from the equilibrium cause price adjustments in domestic prices only, with no feedback effects. This means that international prices are weakly exogenous in this bivariate VECM. In other words, domestic prices adjust when international prices change but not the other way around. The speed of adjustment parameter in the domestic price equation is

Table 2. Johansen cointegration test results. ${ }^{1}$

\begin{tabular}{|c|c|c|c|c|c|c|c|}
\hline \multirow[t]{2}{*}{ Tests } & \multirow{2}{*}{$\begin{array}{l}\text { Null } \\
\text { hypo- } \\
\text { thesis }\end{array}$} & \multicolumn{3}{|c|}{ No linear trend (M2) } & \multicolumn{3}{|c|}{ Linear trend (M4) } \\
\hline & & $\begin{array}{l}\text { Test } \\
\text { statistics }\end{array}$ & $\begin{array}{l}\text { Critical } \\
\text { values }\end{array}$ & Decision & $\begin{array}{l}\text { Test } \\
\text { statistics }\end{array}$ & $\begin{array}{l}\text { Critical } \\
\text { values }\end{array}$ & Decision \\
\hline \multirow[t]{2}{*}{ Trace $\left(\lambda_{\text {trace }}\right)$} & $\mathrm{r}=0$ & $23.288 * *$ & 20.262 & rejected & $27.581 * *$ & 25.872 & rejected \\
\hline & $\mathrm{r} \leq 1$ & 7.369 & 9.165 & not rejected & 10.611 & 12.518 & not rejected \\
\hline \multirow{2}{*}{ Max-eigen value $\left(\lambda_{\max }\right)$} & $\mathrm{r}=0$ & $15.919 * *$ & 15.892 & rejected & $19.473 * *$ & 19.387 & rejected \\
\hline & $\mathrm{r} \leq 1$ & 7.369 & 9.165 & not rejected & 10.611 & 12.518 & not rejected \\
\hline
\end{tabular}

$1 * *$ indicates level of significance at $5 \%$.

Table 3. Estimates of speed of adjustment and testing weak exogeneity and long-run causality. ${ }^{1}$

\begin{tabular}{|c|c|c|c|c|}
\hline \multicolumn{2}{|c|}{$\overline{\text { Speed of adjustment }}$} & \multicolumn{3}{|l|}{ Restrictions in VECM for causality } \\
\hline$\alpha_{1}$ & S.E. & Hypotheses & $\chi 2$-stat & Causality \\
\hline$-0.148 * * *$ & 0.038 & $\begin{array}{l}\mathrm{H}_{0}: \alpha_{1}=0 \text { vs } \mathrm{H}_{1}: \alpha_{1} \neq 0 \\
\mathrm{H}_{0}: \alpha_{2}=0 \text { vs } \mathrm{H}_{1}: \alpha_{2} \neq 0\end{array}$ & $\begin{array}{l}5.858 * *(0.015) \\
0.256(0.613)\end{array}$ & $\begin{array}{l}\text { international prices } \\
\rightarrow \text { domestic prices }^{(a)}\end{array}$ \\
\hline-0.039 & 0.051 & $\begin{array}{l}\mathrm{H}_{0}: \sum \beta_{\mathrm{i}}=0, \alpha_{1}=0 \text { vs } \mathrm{H}_{1}: \sum \beta_{\mathrm{i}} \neq 0, \alpha_{1} \neq 0 \\
\mathrm{H}_{0}: \sum \beta_{\mathrm{i}}=0, \alpha_{2}=0 \text { vs } \mathrm{H}_{1}: \sum \beta_{\mathrm{i}} \neq 0, \alpha_{2} \neq 0\end{array}$ & $\begin{array}{l}38.793 * * *(0.0001) \\
18.645(0.134)\end{array}$ & $\begin{array}{l}\text { international prices } \\
\rightarrow{\text { domestic } \text { prices }^{(\mathrm{b})}}\end{array}$ \\
\hline
\end{tabular}

${ }^{1}$ Parentheses indicate the level of significance; ' $a$ ' indicate long-run causality and ' $b$ ' indicates strong causality; ${ }^{* * *}$ and $* *$ indicates level of significance at 1 and $5 \%$, respectively. S.E. = standard error. 
found to be -0.148 and statistically significant at $1 \%$ level. This implies that about $15 \%$ of deviations are corrected in each month or, in other words, it takes about 6.5 months to restore the long-run equilibrium between domestic and international prices. The speed of adjustment in the international price equation is -0.039 but not statistically significant. The strong causality test result indicates international price influence domestic price only, with no feedback effects. The $\chi^{2}$-statistics are 38.793 and 18.646 for the domestic and the international price equations and statistically significant at $1 \%$ only in the case of domestic price.

There are several strategies to estimate an error correction model (ECM). Engle and Granger (1987) suggest a two-stage method based on the asymptotic independence between the cointegrating relationship and the short-run dynamics. This method is appropriate if the long-run relationship shows asymmetries in the error correction term and is generally applied to large samples. An alternative, particularly in small samples, is to use a one-stage model in which the components of the error correction term are employed directly in the estimating equation. We estimate Equation 9a and 9b using (Zellner's, 1963) SUR because it is possible that domestic and international prices are determined simultaneously. We also estimate the price equations using OLS and use AIC to select the model. We create a Heaviside indicator function (Tsay, 1989) to capture the positive and negative deviations from the long-run equilibrium relationship between domestic and international prices. We employ this specification to test for long-run asymmetry in the error correction term (speed of adjustment). We examine whether the magnitude of the estimated coefficient of the positive deviations equals its negative counterpart. To test the asymmetry in the error correction term, we consider a model with no threshold (case 1, $\gamma=0$ ) and a model that uses threshold estimates (case 2, $\gamma>0$ ).

\subsection{Case 1: $\gamma=0$}

We use the Heaviside indicator function and estimate the Equations 1, 3 and 4. We estimate both domestic price and international price equations. In the first equation we estimate domestic prices as a function of international prices. In the second equation we estimate the international prices as a function of domestic prices. We estimate the TAR and MTAR models and test the cointegration and long-run asymmetries in price transmission. Studies that use the null threshold in TAR and MTAR models include Ghoshray and Ghosh (2011), Sanogo and Amadou (2010), Awokuse and Xiaohong (2009), and Abdulai (2002). The AIC and BIC are used to select the optimal lag length. The TAR and MTAR models are validated by interpreting the F-statistics of joint null hypothesis, $\rho_{1}=\rho_{2}=0$ by $\phi_{\mu}$. The F-statistics of $\phi_{\mu}$ is compared with the values tabulated by Enders and Siklos (2001). In the domestic price equation, results suggest rejecting the null of $\rho_{1}=\rho_{2}=0$ in the TAR model, implying that domestic prices and international prices are cointegrated. The F-statistic is 8.071 and significant at the $5 \%$ level. We find that the sign of parameter estimates $\rho_{1}$ and $\rho_{2}$ are consistent and significant. The model converges when both $\rho_{1}$ and $\rho_{2}$ are negative (necessary conditions) (Enders and Siklos, 2001). The estimates of the adjustment speed $\rho_{1}=-0.091$ and $\rho_{2}=-0.126$ suggest model convergence. However, we are unable to reject the null $\left(\mathrm{H}_{0}: \rho_{1}=\rho_{2}\right)$ of long-term symmetry (Table 4$)$. The estimated F-statistic in the TAR model is 0.428 with a probability value of 0.513 , suggesting that speed of adjustment is not asymmetric. In the case of MTAR model, the null hypothesis of no cointegration (Table 4 ) is accepted. This indicates that the TAR model better represents the data compared to the MTAR model with respect to international prices. We find similar results for the international price equation as a function of domestic prices. In this case, the results from the TAR and the MTAR models indicate that the price series are cointegrated. The estimates of the speed of adjustments $\rho_{1}=-0.091$ and $\rho_{2}=-0.059$ in TAR; $\rho_{1}=$ -0.131 and $\rho_{2}=-0.076$ in MTAR models. The model converges as the sign of both estimates are negative. The null of no cointegration $\left(\rho_{1}=\rho_{2}=0\right)$ is rejected by $\phi_{\mu}$ at the $5 \%$ significant level. However, the null of symmetry in price transmission $\left(\mathrm{H}_{0}: \rho_{1}=\rho_{2}\right)$ cannot be rejected. The Ljung-box Q-statistics up to 4 lags and autoregressive conditional heteroscedasticity $(\mathrm{ARCH})$ tests are performed to test autocorrelation and heteroskedasticity. The results show that the estimated TAR models for both domestic and international prices are free from serial correlation and heteroskedasticity (Table 4). 
Table 4. TAR and MTAR estimates and hypotheses tests. ${ }^{1}$

\begin{tabular}{|c|c|c|c|c|}
\hline \multirow{2}{*}{$\begin{array}{l}\text { Hypotheses tests/parameters/model } \\
\text { diagnostics }\end{array}$} & \multicolumn{2}{|c|}{ Producer prices } & \multicolumn{2}{|c|}{ International prices } \\
\hline & TAR $^{4}$ & MTAR $^{4}$ & TAR & MTAR \\
\hline$\rho_{1}$ & $\begin{array}{l}-0.091^{* *} \\
(-2.554)\end{array}$ & $\begin{array}{c}-0.080^{* *} \\
(-2.399 * * *)\end{array}$ & $\begin{array}{l}-0.091 \text { *** } \\
(-2.580)\end{array}$ & $\begin{array}{l}-0.131 * * * \\
(-2.648)\end{array}$ \\
\hline$\rho_{2}$ & $\begin{array}{l}-0.126^{* * *} \\
(-3.164)\end{array}$ & $\begin{array}{c}-0.166 \\
(-3.837)\end{array}$ & $\begin{array}{c}-0.0599 \\
(-1.495)\end{array}$ & $\begin{array}{c}-0.076 \\
(-1.484)\end{array}$ \\
\hline $\mathrm{AIC}$ & -2.331 & -2.335 & -1.755 & -1.739 \\
\hline \multicolumn{5}{|l|}{ Hypotheses tests } \\
\hline$\phi_{\mu}:$ Cointegration $\mathrm{H}_{0}: \rho_{1}=\rho_{2}$ & $8.071^{* *}$ & $10.044 * * *$ & 4.317 & 4.522 \\
\hline Critical values $^{2}(5 \%)$ & 6.28 & 5.98 & 6.28 & 5.98 \\
\hline Long-term symmetry $\mathrm{H}_{0}: \rho_{1}=\rho_{2}$ & $\begin{array}{c}0.428 \\
(0.513) \\
\end{array}$ & $\begin{array}{c}2.533 \\
(0.112) \\
\end{array}$ & $\begin{array}{c}0.367 \\
(0.544) \\
\end{array}$ & $\begin{array}{c}0.598 \\
(0.439) \\
\end{array}$ \\
\hline \multicolumn{5}{|l|}{ Model diagnostic: } \\
\hline $\mathrm{Q}(4)^{3}$ & 0.515 & 0.660 & 0.841 & 0.873 \\
\hline $\mathrm{ARCH}^{4}$ test & $\begin{array}{c}0.134 \\
(0.713)\end{array}$ & $\begin{array}{c}0.427 \\
(0.513)\end{array}$ & $\begin{array}{c}0.103 \\
(0.748)\end{array}$ & $\begin{array}{c}1.525 \\
(0.217)\end{array}$ \\
\hline \multicolumn{5}{|c|}{$\begin{array}{l}{ }^{1} \text { Parentheses in first panel indicate the } t \text {-values; parentheses in second and third panels indicate the } P \text {-values; } * * * \text { and } * * \text { indicates } \\
\text { level of significance at } 1 \text { and } 5 \% \text {, respectively. } \\
{ }^{2} \text { Critical values are from the Enders and Sikolos (2001). } \\
{ }^{3} \text { Indicate Ljung-Box statistics, Q(P) that the first P of residuals serial correlations are jointly zero. } \\
{ }^{4} \mathrm{ARCH}=\text { autoregressive conditional heteroscedasticity; MTAR = momentum-threshold autoregressive; TAR = threshold auto- }\end{array}$} \\
\hline
\end{tabular}

\subsection{Case 2: $\gamma>0$}

The threshold $\gamma$ is estimated following Chan (1993). Both the TAR and MTAR models for the domestic and international prices are estimated. Similar to case 1, the equations for both domestic and international prices are estimated separately to examine the threshold effects. We identify optimal lag length using BIC. The consistent-MTAR model fits better to the data, hence, we present the results from the consistent-MTAR model. The model is validated by interpreting the F-statistics of joint null hypothesis, $\rho_{1}=\rho_{2}=0$ by $\phi_{\mu}$. The F-statistics of $\phi_{\mu}$ is compared with the values tabulated by Enders and Sikolos (2001). The test results reject the null of $\rho_{1}=\rho_{2}=0$ implying that the domestic prices and international prices are cointegrated. The signs of estimates $\rho_{1}$ and $\rho_{2}$ are consistent and significant at 5\% level (Table 5). The parameter estimates are $\rho_{1}$ $=-0.064$ and $\rho_{2}=-0.186$ suggest model convergence. The BIC is used to select the optimal lag length. The delay parameter ' $d$ ' is identified based on the Tsay (1989) (i.e. choosing ' $d$ ' that maximizes the F-statistics (Goodwin and Holt, 1999; Goodwin and Piggot, 2001; Lee and Gómez, 2013). In the domestic price equation, the Tsay (1989) test finds strong evidence of non-linearity in $\mu_{t-1}$. The estimated F-statistics 3.880 implies that the null of a liner AR process in the cointegrated vector is rejected at $5 \%$ level. The percentage share of observation in the inside regime (i.e. deviations from the long-run equilibrium in the interval $[-\gamma$, $\gamma]$ ) is 47 and outside regime is 53. Since, we find the nonlinearities in the error correction term, we proceed to estimate the threshold $\gamma$ using Chan's (1993) grid search approach. The threshold values are estimated through a search over all possible threshold values minimizing sum of square errors (SSE). The estimated threshold is 0.0489 that minimizes the SSE. Hansen (1997) argues that conventional test is not appropriate since null of linearity in the AR process does not follow a standard distribution. Hansen proposes a Chow test for threshold value using simulations and provides asymptotic $P$-values based on bootstrap (Goodwin and Holt, 1999; Hansen, 1997; Lee and Gómez, 2013). Hansen (1997) tests also reject the null of no threshold effects at 5\% significance level. The max-F statistics is 6.282 . This result provides additional evidence of threshold effects in the cointegrating vector between the international and domestic prices. The F-statistics to test the null of symmetry (in Table 5) confirms the existence of the long-run asymmetries across regimes 
Table 5. Consistent momentum threshold autoregressive (AR) estimates. ${ }^{1}$

\begin{tabular}{|c|c|c|}
\hline \multirow[t]{2}{*}{ Estimates } & \multicolumn{2}{|c|}{ Normalized equations } \\
\hline & Domestic prices & International prices \\
\hline Optimal lag length & $0(\mathrm{SBC})$ & $1(\mathrm{SBC})$ \\
\hline Delay parameter $(d)$ & 10 & 10 \\
\hline Tsay test and probability value (F-stat) $\left(\mathrm{H}_{0}\right.$ : No linear process) & $3.880 * *(0.050)$ & $3.135 * *(0.045)$ \\
\hline $\begin{array}{l}\text { Threshold cointegration (Hansen, 1997) (max F-statistics and } \\
\text { bootstrap } P \text {-values) }\end{array}$ & $6.282 * *(0.036)$ & $1.4841(0.873)$ \\
\hline Estimated threshold $(\gamma)$ using Chan`s (1993) grid search & 0.0489 & 0.0213 \\
\hline Cointegration $\left(\mathrm{H}_{0}: \rho_{1}=\rho_{2}\right)($ F-statistics $)$ & $12.270 * * *(0.000)$ & $8.378 * * *(0.000)$ \\
\hline Long-run symmetry across regimes $\left(\mathrm{H}_{0}: \rho_{1}=\rho_{2}\right)$ (F-statistics) & $5.270 * *(0.022)$ & $3.693 *(0.055)$ \\
\hline$\rho_{1}$ & $-0.0648 * *(0.05)$ & $-0.110 * * *(0.000)$ \\
\hline$\rho_{2}$ & $-0.1860 * * *(0.000)$ & $-0.0187(0.763)$ \\
\hline Number and percentage of observation in 'IN' regime & $141(47.16 \%)$ & $250(83.6 \%)$ \\
\hline Number and percentage of observation in 'OUT' regime & $158(52.84 \%)$ & $49(16.4 \%)$ \\
\hline Akaike Information Criterion (AIC) & -2.347 & -1.771 \\
\hline Schwarz Bayesian Criterion (SBC) & -2.298 & -1.709 \\
\hline
\end{tabular}

supporting the null of presence of nonlinearities in the error correction term. We are unable to accept the null $\left(\mathrm{H}_{0}: \rho_{1}=\rho_{2}\right)$ of long-term symmetry. We draw similar conclusions when we estimate international prices as a function of domestic prices (last column in Table 5). The estimates of speed of adjustment are $\rho_{1}=-0.110$ and $\rho_{2}=-0.018$. Only the estimate $\rho_{1}$ is statistically significant at the $1 \%$ level. The model converges, as the signs of both parameters are negative. In addition, we reject the null of no cointegration $\left(\rho_{1}=\rho_{2}=0\right)$ by $\phi_{\mu}$ at $1 \%$ significant level. We find the threshold value is 0.021 . We find nonlinearities in the error correction, but no evidence of asymmetry and observations are well distributed ( 84 and $16 \%$ in 'IN' and 'OUT' regimes, respectively).

Table 6 presents OLS parameter estimates from the estimated ATECM for both domestic prices and international prices. We estimate the ATECM using both Zellner (1963) SUR and OLS. According to the AIC statistics, the OLS model is a better fit than SUR, hence, only the OLS results are presented. Also, the paper focuses primarily on the domestic price equation, given that our objective is to examine asymmetries in price transmission from international to domestic prices and that the feedback from domestic to international prices is expected to be quite modest. The results indicate that the speed of adjustment to negative price deviations $\left(\rho_{2}\right)$ is faster than the speed of adjustment to positive price deviations $\left(\rho_{1}\right)$ in absolute terms. The estimated coefficients are negative, as predicted. The estimates of the adjustment speed $\rho_{1}=-0.058$ and $\rho_{2}$ $=-0.135$ suggest model convergence. This implies that positive price deviations in previous periods tend to persist compared to negative price deviations from the long-run equilibrium. Next, we focus to the short-run price transmission asymmetries. The estimates of the positive and negative price changes in contemporary international prices 0.161 and 0.408 are significant at 5 and 1\%, respectively. Additionally, to further check the model, we estimate international price equation with respect to domestic prices and find that only the estimate $\rho_{2}$ is statistically significant. The minimum AIC value (-2.53) in domestic price equation advocates the model selection. The differences in short-run price transmission can be discussed in the context of the structure and performance in the orange supply chain. 
Table 6. OLS estimates from the asymmetric threshold ECMs. ${ }^{1}$

\begin{tabular}{|c|c|c|c|c|c|c|}
\hline \multirow[t]{2}{*}{ Variables } & \multicolumn{3}{|l|}{$\Delta p p_{t}$} & \multicolumn{3}{|l|}{$\Delta w p_{t}$} \\
\hline & Estimates & $t$-statistics & $P$-values & Estimates & $t$-statistics & $P$-values \\
\hline Constant & $0.0255 * * *$ & 2.574 & 0.010 & 0.003 & 0.278 & 0.780 \\
\hline$\mu_{t-1}^{\mathrm{IN}}$ & $-0.058 *$ & -1.752 & 0.080 & $-0.087 * * *$ & -3.057 & 0.002 \\
\hline$\mu^{\mathrm{OUT}}{ }_{\mathrm{t}-1}^{\mathrm{t}-1}$ & $-0.135 * * *$ & -3.399 & 0.0008 & 0.046 & 0.758 & 0.448 \\
\hline$\Delta \mathrm{wp}_{\mathrm{t}}^{+}$ & $0.161 * *$ & 2.239 & 0.025 & - & - & - \\
\hline$\Delta w_{p_{t}^{-}}^{-}$ & $0.408 * * *$ & 5.041 & 0.000 & - & - & - \\
\hline$\Delta w p_{t-1}^{+}$ & -0.059 & -0.806 & 0.420 & -0.161 & -1.484 & 0.138 \\
\hline$\Delta w p_{t-1}^{-}$ & 0.112 & 1.335 & 0.182 & -0.104 & -0.878 & 0.380 \\
\hline$\Delta \mathrm{wp}_{\mathrm{t}-2}^{+}$ & 0.024 & 0.327 & 0.743 & 0.044 & 0.416 & 0.677 \\
\hline$\Delta w p_{t-2}^{-}$ & -0.096 & -1.136 & 0.256 & 0.097 & 0.818 & 0.413 \\
\hline$\Delta w p_{t-3}^{+}$ & 0.086 & 1.168 & 0.243 & 0.034 & 0.320 & 0.749 \\
\hline$\Delta w p^{-}$ & 0.033 & 0.407 & 0.683 & 0.145 & 1.257 & 0.209 \\
\hline$\Delta \mathrm{pp}^{+}{ }_{\mathrm{t}}$ & - & - & - & $0.617^{* * *} *$ & 4.688 & 0.000 \\
\hline$\Delta \mathrm{pp}_{\mathrm{t}}^{-}$ & - & - & - & $0.501 * * *$ & 4.355 & 0.000 \\
\hline$\Delta \mathrm{pp}_{\mathrm{t}-1}^{+}$ & 0.054 & 0.556 & 0.578 & 0.047 & 0.355 & 0.722 \\
\hline$\Delta p p_{t-1}^{-}$ & 0.039 & 0.461 & 0.645 & $0.300 * *$ & 2.505 & 0.012 \\
\hline$\Delta \mathrm{pp}^{+}{ }_{\mathrm{t}-2}$ & $-0.216^{* *}$ & -2.229 & 0.026 & -0.149 & -1.110 & 0.267 \\
\hline$\Delta \mathrm{pp}_{\mathrm{t}-2}^{-}$ & 0.040 & 0.476 & 0.634 & -0.011 & -0.095 & 0.923 \\
\hline$\Delta \mathrm{pp}^{+}{ }_{\mathrm{t}-3}$ & 0.021 & 0.220 & 0.825 & 0.074 & 0.550 & 0.582 \\
\hline$\Delta \mathrm{pp}_{\mathrm{t}-3}^{-}$ & $-0.148^{*}$ & -1.771 & 0.077 & -0.053 & -0.449 & 0.653 \\
\hline$\Delta \mathrm{er}^{+}{ }_{\mathrm{t}}$ & $1.722 * * *$ & 4.116 & 0.000 & 0.663 & 1.084 & 0.279 \\
\hline$\Delta \mathrm{er}_{\mathrm{t}}^{-}$ & $0.732 * * *$ & 4.155 & 0.000 & -0.302 & -1.163 & 0.245 \\
\hline$\Delta \mathrm{er}_{\mathrm{t}-1}^{+}$ & -0.118 & -0.272 & 0.785 & -0.676 & -1.109 & 0.268 \\
\hline$\Delta \mathrm{er}_{\mathrm{t}-1}^{-}$ & -0.286 & -1.528 & 0.127 & 0.308 & 1.187 & 0.236 \\
\hline$\Delta \mathrm{er}^{+}{ }_{\mathrm{t}-2}^{\mathrm{t}-2}$ & -0.034 & -0.086 & 0.931 & $1.009 *$ & 1.808 & 0.071 \\
\hline$\Delta \mathrm{er}_{\mathrm{t}-2}^{-}$ & 0.272 & 1.355 & 0.176 & 0.043 & 0.152 & 0.879 \\
\hline$\Delta \mathrm{er}^{+}{ }_{\mathrm{t}-3}^{\mathrm{l}-2}$ & 0.644 & 1.650 & 0.100 & -0.169 & -0.303 & 0.761 \\
\hline$\Delta \mathrm{er}_{\mathrm{t}-3}^{-}$ & 0.178 & 0.895 & 0.371 & -0.196 & -0.702 & 0.483 \\
\hline $\mathrm{rf}_{\mathrm{t}-1}$ & -0.00002 & -0.640 & 0.522 & 0.00001 & 0.273 & 0.785 \\
\hline $\mathrm{rf}_{\mathrm{t}-2}^{\mathrm{t}-1}$ & -0.00003 & -0.734 & 0.463 & 0.00001 & 0.195 & 0.845 \\
\hline $\mathrm{rf}_{\mathrm{t}-3}$ & $-0.00011 * *$ & -2.503 & 0.012 & -0.00002 & -0.462 & 0.644 \\
\hline $\mathrm{AIC}^{2}$ value & -2.530 & & & -1.848 & & \\
\hline
\end{tabular}

The models are subject to model diagnostics. The model diagnostic and model selection criteria such as ARCH, Ljung Box and Ramsey RESET tests suggest that there are no problems of heteroskedasticity, and autocorrelation. The estimated models are stable and free from specification biases. Additionally, we use model selection criteria to select the model. The models with three lags are free from autocorrelation and heteroskedasticity. Also, the AIC value is minimum with three lags. These results advocate our final model which is ATECM for domestic prices with respect to international prices. The AIC value is -2.530 for domestic price equation. The AIC values are 2.526 and -2.501 with two and four lags, respectively and the values are higher than the value found using ATECM (3). The directions of the results are similar for international price equation with respect to domestic prices (Table 7). So, we conclude that the ATECM for the domestic prices with three lags seems appropriate, i.e. ATECM (3). 
Table 7. Results from the model diagnostic and selection of model.

\begin{tabular}{|c|c|c|c|c|}
\hline \multirow[t]{2}{*}{$\overline{\text { Tests }^{1}}$} & \multicolumn{2}{|c|}{$\triangle \mathrm{PP}_{\mathbf{t}}: \operatorname{ATECM}(3)$} & \multicolumn{2}{|c|}{$\Delta \mathrm{WP}_{\mathrm{t}}: \operatorname{ATECM~(3)}$} \\
\hline & Estimates & $P$-values & Estimates & $P$-values \\
\hline $\mathrm{ARCH}$ & 1.464 & 0.225 & 0.208 & 0.647 \\
\hline Ljung-Box Q(4) & 0.299 & 0.990 & 0.112 & 0.990 \\
\hline Ramsey RESET & 2.028 & 0.1555 & 0.475 & 0.491 \\
\hline \multirow[t]{3}{*}{ AIC of ATECM (2) } & -2.526 & & -1.821 & \\
\hline & -2.531 & & -1.848 & \\
\hline & -2.501 & & -1.802 & \\
\hline
\end{tabular}

${ }^{1} \mathrm{AIC}=$ Akaike Information Criterion; ARCH $=$ autoregressive conditional heteroscedasticity; ATECM $=$ asymmetric threshold error correction model.

The F-statistics of the asymmetric threshold ECM is presented in Table 8 . We find that PTAs are present both in short- and long-run price dynamics. The speed of adjustment in outside regime is bigger than the speed of adjustment in inside regime. The F-statistics 6.234 to the null of symmetry in speed of adjustment is rejected at $5 \%$ level only for the domestic price equation with respect to international prices. Also, we can reject the null hypothesis $\Delta W P_{(0) t}^{+}=\Delta W P_{(0) t}^{-}$. This implies that, in the short-run, domestic prices adjust differently to positive contemporaneous international prices compared to negative changes. Finally, we find that the joint F-statistics rejects the null of sum of coefficients of all positive price lags are equal to sum of coefficients of all negative changes. In addition, we can reject the null of $\Delta E R_{(L D) t}^{+}=\Delta E R_{(L D) t}^{-}$. This implies that in the short-run, domestic prices adjust differently to positive contemporaneous exchange rate changes compared to negative changes. However, from the results we can conclude the existence of long- and shortrun asymmetries in the price transmission between international-to-domestic prices. It is important to notice that we use the exchange rate just to normalize the domestic prices and that the effects of exchange rate were not considered because they were not significant for market behavior. As for the weather variable, rainfall was used as control variable looking at adjustment of the model.

Table 8. Tests of asymmetries in the short- and long-run price transmissions. ${ }^{1}$

\begin{tabular}{|c|c|c|c|c|c|}
\hline \multicolumn{3}{|l|}{$\Delta \mathbf{P P}_{\mathrm{t}}$} & \multicolumn{3}{|l|}{$\Delta \mathbf{W P}_{\mathrm{t}}$} \\
\hline Hypotheses & F-stat & $P$-values & Hypotheses & F-stat & $P$-values \\
\hline $\mathrm{H}_{0}: \mu_{\mathrm{t}-1}^{\mathrm{OUT}(\mathrm{p})}=\mu_{\mathrm{t}-1}^{\mathrm{IN}(\mathrm{p})}$ & $6.234 * *$ & 0.011 & $\mathrm{H}_{0}: \mu_{\mathrm{t}-1}^{\mathrm{OUT}(\mathrm{w})}=\mu_{\mathrm{t}-1}^{\mathrm{IN}(\mathrm{w})}$ & $4.212^{* *}$ & 0.041 \\
\hline $\mathrm{H}_{0}: \Delta \mathrm{WP}_{\mathrm{t}}^{+}=\Delta \mathrm{WP}_{\mathrm{t}}^{-}$ & $3.595 * *$ & 0.050 & $\mathrm{H}_{0}: \Delta \mathrm{PP}_{\mathrm{t}}^{+}=\Delta \mathrm{PP}_{\mathrm{t}}^{-}$ & 0.370 & 0.543 \\
\hline $\mathrm{H}_{0}: \sum_{\mathrm{i}=0}^{3} \beta_{\mathrm{i}} \Delta \mathrm{WP}_{\mathrm{t}-\mathrm{i}}^{+}=\sum_{\mathrm{i}=0}^{3} \beta_{\mathrm{i}} \Delta \mathrm{WP}_{\mathrm{t}-\mathrm{i}}^{-}$ & $5.626^{* *}$ & 0.0184 & $\mathrm{H}_{0}: \sum_{\mathrm{i}=0}^{3} \beta_{\mathrm{i}} \Delta \mathrm{PP}_{\mathrm{t}-\mathrm{i}}^{+}=\sum_{\mathrm{i}=0}^{3} \beta_{\mathrm{i}} \Delta \mathrm{PP}_{\mathrm{t}-\mathrm{i}}^{-}$ & 0.232 & 0.631 \\
\hline $\mathrm{H}_{0}: \Delta \mathrm{ER}_{(\mathrm{LD}) t}^{+}=\Delta \mathrm{ER}_{(\mathrm{LD}) \mathrm{t}}^{-}$ & $4.036^{* *}$ & 0.045 & $\mathrm{H}_{0}: \Delta \mathrm{ER}^{+}(\mathrm{LD}) t=\Delta \mathrm{ER}_{(\mathrm{LD}) \mathrm{t}}^{-}$ & 1.844 & 0.176 \\
\hline
\end{tabular}

${ }^{1}$ We report the international price equation as well to further to check if positive and negative adjustment to disequilibrium error is equal to zero. $* *$ indicates level of significance at $5 \%$. 


\section{Conclusions}

Price transmission asymmetries can provide valuable information for private and public decision makers about supply chain behavior. We estimate threshold asymmetric error correction models to statistically estimate the threshold and test for long- and short-run PTAs in the Brazilian orange supply chain. The analysis focuses on the impact of changes in international FCOJ prices on domestic prices. Our results uncovered differences in short- and long-run price adjustment behavior. Our results suggest that threshold effects exist in the speed of adjustment towards long-run equilibrium and adjustment are different for positive and negative deviations from the equilibrium. Our results indicate that the industry immediately transmitted price decreases whereas price increases are transmitted in a three-month lag period. We also find evidence of short-run price transmission asymmetries. Therefore, the findings provide evidence that the processing sector may have exerted some degree of market power over orange growers in Brazil during the period of analysis. That is, domestic prices received the Brazilian orange growers decreased quickly in response to lower prices of FCOJ prices. In contrast, domestic prices increased relatively slow (i.e. restored the marketing margin equilibrium in a three-month period) in response to higher international prices of FCOJ. This is not surprising, given that the Brazilian orange supply chain exhibits high levels of concentration in the orange processing sector and a relatively large number of independent orange growers.

Hence our findings about the asymmetry of price transmission within the Brazilian citrus sector verify the advantageous position of orange processors when the international price of FCOJ is rising and excluding growers from fully benefitting from higher international prices. Unfortunately, some attempts for dialog between producers and processors to establish instruments for the formation of prices with sharing of risks and transparency have failed. This underscores the need for policies aimed at incentivizing the utilization of contracts between processors and growers that take into account a fair pass-through of shocks that affect prices along the supply chains.

Although our results are valuable for practitioners and policymakers, additional research is required to further understand price transmission and its implications for the Brazilian orange value chain. For example, replicating the analysis using Brazilian FCOJ prices in place of international wholesale orange prices would be useful. If there were less asymmetry in price transmission directly between the international and domestic FCOJ prices, it would bolster the conclusion that FCOJ producers are benefiting disproportionately from international price increases. Additionally, future research could focus on developing dynamic structural models incorporating supply and demand to further analyze the role of price transmission mechanisms in industry conduct and performance.

\section{Conflict of interest}

There is no conflict of interest.

\section{Acknowledgements}

The earlier version of this paper was written when the first author was a Fulbright Visiting Scholar at the Charles H. Dyson School of Applied Economics and Management, Cornell University, Ithaca, NY 14853, USA.

\section{References}

Abdulai, A. 2000. Spatial price transmission and asymmetry in the Ghanaian maize market. Journal of Development Economics 63: 327-349.

Abdulai, A. 2002. Using threshold cointegration to estimate asymmetric price transmission in the Swiss pork market. Applied Economics 34(6): 679-687. 
Alam, M.J., A.M. McKenzie, I.A. Begum, J. Buysse, E. Wailes and G. Van Huylenbroeck. 2016. Asymmetry price transmission in the deregulated rice markets in Bangladesh: asymmetric error correction model. Agribusiness 32(4): 498-511.

Appel, V. 1992. Asymmetries in der preistransmission. Agrarwirtschaft Sonderheft 135: 178-213.

Awokuse, T.O. and W. Xiaohong. 2009. Threshold effects and asymmetric price adjustments in U.S. dairy markets. Canadian Journal of Agricultural Economics 57: 269-286.

Azzam, A.M. 1999. Asymmetry and rigidity in farm-retail price transmission. American Journal of Agricultural Economics 81(3): 525-533.

Bailey, D. and B.W. Brorsen. 1989. Price asymmetry in spatial fed cattle markets. Western Journal of Agricultural Economics 14(2): 246-252.

Balke, N.S., S.P.A. Brown and M.K. Yücel. 1998. Crude oil and gasoline prices: an asymmetric relationship? Federal Reserve Bank of Dallas, Dallas, TX, USA. Available at: https://www.dallasfed.org/ /media/ documents/research/er/1998/er9801a.pdf

Ben-Kaabia, M., J.M. Bil and M. Ameur. 2005. Vertical integration and non-linear price adjustments: the Spanish poultry sector. Agribusiness 21(2): 253-271.

Bloomberg. 2014. Commodity price table for FCOJ 01/01/1996 to 12/31/2014. Bloomberg database. Available at: https://johnson.library.cornell.edu/database/bloomberg/

Borenstein, S., A.C. Cameron and R. Gilbert. 1997. Do gasoline prices respond asymmetrically to crude oil price changes? Quarterly Journal of Economics 112(1): 305-339.

Boyd, M.S. and B.W. Brorsen. 1988. Price asymmetry in the U.S. pork marketing channel. North Central Journal of Agricultural Economics 10: 103-110.

CEPEA. 2014. Hortifruti Brasil. HfBrasil, Centre of Advanced Studies in Applied Economics. Available at: https://www.hfbrasil.org.br/br/banco-de-dados-precos-medios-dos-hortifruticolas.aspx

Chan, K.S. 1993. Consistency and limiting distribution of the least square estimator of a threshold autoregressive model. The Annals of Statistics 21: 520-533.

CITRUSBR. National Association of Citric Juice Exporters. Exportações Brasileiras de suco de laranja mundo. Available at: https://citrusbr.com/estatisticas/exportacoes/

Elliott, G. 1999. Efficient tests for a unit root when the initial observation is drawn from its unconditional distribution. International Economic Review 40(3): 767-783.

Elliott, G., T.J. Rothenberg and J.H. Stock. 1996. Efficiency test for an autoregressive unit root. Econometrica 64(4): 813-834.

Enders, W. and C.W.J. Granger 1998. Unit-root tests and asymmetric adjustment with an example using the term structure of interest rates. Journal of Business \& Economic Statistics 16: 304-311.

Enders, W. and P. Siklos. 2001. Cointegration and threshold adjustment. Journal of Business and Economic Statistics 19: 166-175.

Engle, R.F. and C.W.J. Granger. 1987. Cointegration and error correction: representation, estimation, and testing. Econometrica 55(2): 251-276.

Figueiredo, A.M., H.M. de Souza Filho and L.F. de Oriai Paullilo. 2013. Analise das margens e transmissao de precos no sistema agroindustrial do suco de laranja no Brasil. Revista de Economia e Sociologia Rural 51(2): 331-350. https://doi.org/10.1590/S0103-20032013000200007

Frost, D. and R. Bowden. 1999. An asymmetry generator for error-correction mechanisms, with application to bank mortgage-rate dynamics. Journal of Business and Economic Statistics 17(2): 253-263.

Ghoshray, A. and M. Ghosh. 2011. How integrated is the Indian wheat market? Journal of Development Studies 47(10): 1574-1594.

Goetz, L., S. Von Cramon-Taubadel and Y. Kachel. 2008. Measuring price transmission in the international fresh fruit and vegetable supply chain: the case of Israeli grapefruit exports to the EU (No. 8882016-65037). Discussion Paper 42833. Department of Agricultural Economics and Management, Hebrew University of Jerusalem, Jerusalem, Israel.

Goodwin, B.K. and M.T. Holt. 1999. Asymmetric adjustment and price transmission in the U.S. beef sector. American Journal of Agricultural Economics 81(3): 630-637.

Goodwin, B.K. and N.E. Piggot. 2001. Spatial market integration in the presence of threshold effects. American Journal of Agricultural Economics 83(2): 302-317. 
Granger, C.W.J. and T.H. Lee. 1989. Investigation of production, sales and inventory relationships using multi-cointegration and non-symmetric error correction models. Journal of Applied Econometrics 4: S145-S159.

Hansen, B.E. 1997. Inference in TAR models. Studies in Nonlinear Dynamics and Economics 2: 1-14.

Hansmire, M.R. and L.S. Willet. 1992. Price transmission processes: a study of price lags and asymmetric price response behaviour for New York Red Delicious and McIntosh Apple. Cornell University, Ithaca, NY, USA.

Houck, P.J. 1977. An approach to specifying and estimating nonreversible functions. American Journal of Agricultural Economics 59(3): 570-572.

Integrated Agrometeorological Information Center (CIIAGRO). 2021. Resenha: Barretos no periodo de 01/09/1992 até 01/08/2021. Available at: http://www.ciiagro.sp.gov.br/ciiagroonline/Listagens/ Resenha/LResenhaLocal.asp

Johansen, S. 1988. Statistical analysis of cointegration vectors. Journal of Economic Dynamics and Control 12: 231-254.

Johansen, S. 1992a. Cointegration in partial systems and the efficiency of single-equation analysis. Journal of Econometrics 52(1): 389-402.

Johansen, S. 1992b. Determination of cointegration rank in the presence of a linear trend. Oxford Bulletin of Economics and Statistics 54(4): 383-397.

Johansen, S. 1995. Likelihood based inference in cointegrated vector autoregressive models. Oxford University Press, Oxford, UK.

Kinnucan, H.W. and O.D. Forker. 1987. Asymmetry in farm-retail price transmission for major dairy products. American Journal of Agricultural Economics 69(2): 285-292.

Kwiatowski, D., P.C.B. Phillips, P. Schmidt and Y. Shin. 1992. Testing the null hypothesis of stationarity against the alternative of a unit root: how sure are we that economic time series have a unit root? Journal of Econometrics 54(1): 159-178.

Lass, D.A. 2005. Asymmetric response of retail milk prices in the northeast revisited. Agribusiness 21(4): 493-508.

Lee, J. and M. Gomez. 2013. Impacts of the end of the coffee export quota system on international-to-retail price transmission. Journal of Agricultural Economics 64(2): 343-362.

Levy, D., M. Bergen, S. Dutta and R. Venable. 1997. The magnitude of menu costs: direct evidence from large U.S. supermarket chains. Quarterly Journal of Economics 112(3): 791-825.

Mankiw, N.G. and D.H. Romer. 1991. New Keynesian economics. MIT Press, Cambridge, MA, USA.

McLaughlin, E.W. 2006. U.S. retailing: more competitive than in Europe? Interact 1: 22-25.

Meyer, J. and S. Von Cramon-Taubadel. 2004. Asymmetric price transmission: a survey. Journal of Agricultural Economics 55(3): 581-611.

Miller, D.J. and M.L. Hayenga. 2001. Price cycles and asymmetric price transmission in the U.S. pork market. American Journal of Agricultural Economics 83(3): 551-562.

Neumark, D. and S.A. Sharpe. 1992. Market structure and the nature of price rigidity: evidence from the market for consumer deposits. Quarterly Journal of Economics 107(2): 657-680.

Neves, M.F., V.G. Trombin and R.B. Kalaki. 2014. Peeling back the citrus in Brazil: mapping and quantification of the Brazilian citrus chain. Citrus Research \& Technology, Cordeirópolis 35(2): 45-60.

Neves, M.F., V.G. Trombin, R.B. Kalaki and F.F. Lopes. 2013. Competitiveness of the orange juice chain in Brazil. International Food and Agribusiness Management Review 16: 34-49.

Peltzman, S. 2000. Prices rise faster than they fall. Journal of Political Economy 108(3): 466-502.

Petrucelli, J. and S. Woolford. 1984. A threshold AR(1) model. Journal of Applied Probability 21(2): 270-286.

Romain, R., M. Doyon and M. Frigon. 2002. Effects of state regulation on marketing margins and price transmission asymmetry: evidence from the New York City and upstate New York fluid milk markets. Agribusiness 18(3): 301-315.

Sanjuán, A.I. and J.M. Gil. 2001. Price transmission analysis: a flexible methodological approach applied to European pork and lamb markets. Applied Economics 33(1): 123-131.

Sanogo, I. and M.M. Amodou. 2010. Rice market integration and food security in Nepal: the role of crossborder trade with India. Food Policy 35: 312-322. 
Santos, C.V. 2003. Vertical integration, concentration and exclusion within the Sao Paulo citrus sector. PhD-thesis, Federal University of Sao Carlos (UFSCar), São Carlos, SP, Brazil, 171 pp.

Serra, T. and B.K. Goodwin. 2003. Transmission and asymmetric adjustment in the Spanish dairy sector. Applied Economics 35(18): 1889-1899.

Silva, A.F., G.S. De Barros and M. Boteon. 2017. Price analyses of the Brazilian citrus supply chain. Journal of Food Science and Engineering 7: 49-58.

Tsay, R. 1989. Testing and modelling threshold autoregressive process. Journal of the American Statistical Association 84: 231-240.

Von Cramon-Taubadel, S. 1998. Estimating asymmetric price transmission with the error correction representation: an application to the German pork market. European Review of Agricultural Economics 25(1): 1-18.

Von Cramon-Taubadel, S. and J.P. Loy. 1996. Price asymmetry in the international wheat market: comment. Canadian Journal of Agricultural Economics 44(3): 311-317.

Von Cramon-Taubadel, S. and J.P. Loy. 1999. The identification of asymmetric price transmission processes with integrated time series. Jahrbucher fur Nationalokonomie und Statistik 208(1-2): 85-106.

Ward, R.W. 1982. Asymmetry in retail, whole, and shipping point pricing for fresh vegetables. American Journal of Agricultural Economics 64(2): 205-212.

Wolffram, R. 1971. Positivistic measures of aggregate supply elasticities: some new approaches - some critical notes. American Journal of Agricultural Economics 53(2): 356-359.

Xia, T. 2009. Asymmetric price transmission, market power, supply and demand curvature. Journal of Agricultural and Food Industrial Organization 7(1).

Zellner, A. 1963. An efficient method of estimating seemingly unrelated regressions and tests of aggregation bias. Journal of the American Statistical Association 57(298): 500-509.

Zhang, P., S.M. Fletcher and D.H. Carley. 1995. Peanut price transmission asymmetry in peanut butter. Agribusiness 11(1): 13-20.

Zivot, E. and D.W.K. Andrews. 1992. Further evidence on the great crash, the oil-price shock and the unit root hypothesis. Journal of Business and Economic Statistics 10(3): 251-270. 